\title{
SPECIFIC PSYCHOLOGICAL CHARACTERISTICS OF IMPROVING THE CONTENT OF PHYSICS EDUCATION ON THE BASIS OF SOLVING NON-STANDARD PROBLEMS
}

\author{
Yusup Ganievich Mahmudov \\ Doctor Of Pedagogical Sciences, Professor, Department Of General Physics, Termez State University, Uzbekistan \\ Gayrat Fayzullaevich Raimov \\ Senior Lecturer, Department Of Theoretical Physics, Termez State University, Uzbekistan
}

\section{ABSTRACT}

This article logically and consistently describes the specific psychological features of improving the content of physics education on the basis of solving non-standard problems.

KEYWORDS:- Interest, process, activity, result, abstract, thinking, education, upbringing, desire, memory, function, compensation, ability, skill, knowledge, practice, opportunity, emotion.

\section{INTRODUCTION}

Gaining the interest of general secondary school students in physics is a pedagogical process. Under the guidance of a teacher, students acquire the knowledge, skills, competencies to solve nonstandard problems of their theoretical knowledge structured from the basics of this subject. In general, the acquisition of interest in students is a two-way process, which combines the activities of the teacher (teaching) and the activities of students (learning). In particular, general secondary school students develop an interest in physics in the process of solving nonstandard problems, forming in them a scientific worldview, developing abstract thinking, developing logical observation, and most importantly, the ability to apply theoretical knowledge in practice.
Successful solution of educational problems of general secondary school students in the development of interest in physics in the process of solving non-standard problems, will and emotional qualities (independence in discussion and work, initiative, assertiveness, goalorientation, level of emotional arousal, strength and depth of emotional anxiety, emotional stability), cognitive activity and mental development characteristics (attention, memory, speech and thinking skills).

\section{T HE MAIN PART}

The driving force behind the mental development of a young schoolboy is the direct dialectical contrast between novelty and antiquity. These contradictions arise in the process of teaching and educating students, and they are gradually resolved. For example, the 
CURRENT RESEARCH JOURNAL OF PEDAGOGICS 2(7): 16-18, July 2021

DOI: https://doi.org/10.37547/pedagogics-crjp-02-07-04

ISSN 2767-3278

(C)2021 Master Journals

Crossref dof 81 Google

Accepted 23thJuly, 2021 \& Published 28 ${ }^{\text {th }}$ July, 2021

demands that arise in the learning process are the contradictions between the growing demands of older students and their ability to satisfy them and the current level of mental development.

The resolution of all conflicts occurs in the process of mental activity. As a result, the young child enters a higher stage of intellectual development. At certain stages of a young child's development, the most favorable conditions for the development of the psyche are created. It is assumed that there are optimal time intervals, i.e. periods, in the formation and development of certain types of mental activity. Such periods are called the sensitive period in the research of L.S.Vygotsky and A.N. Leontev. For example, the sensitive period for speech development requires 1 to 5 years, 11-13 years for the formation of model thinking, and 13-15 years for scientific (physical) thinking. As the individual psyche develops, integrity, unity, stability increase, and in provard, their integration takes place. This leads to the emergence of one or another of the personality traits. The psyche has the ability to change purposefully and flexibility in the context of teaching and upbringing. If any of its functions do not develop well, other functions develop rapidly. For example, visual defects are compensated by the strong development of hearing analyzers, free memory can be compensated by greater organization and accuracy in work.

As a criterion for the development of interest in solving non-standard problems in physics in general secondary school students, psychologists put forward the following description:

1) Speed of solving or mastering non-standard problems and mastering them;

2) The slowness of thinking, which is determined by the number of comments, on the basis of which students learn new laws for themselves;
3) Level of analytical activity in solving nonstandard problems;

4) Methods of mastering the mental activity formed in the solution of other non-standard problems on the basis of solving nonstandard problems;

5) Knowledge of the systematization and generalization of theoretical knowledge and practical skills, competencies acquired independently in solving non-standard problems.

A high level of interest is characterized by the generalization of mental methods. This creates conditions for solving non-standard problems from one non-standard problem to another. For example, the application of the study of "Pascal's law", "Atmospheric pressure" or "Archimedean force", "Swimming of bodies" to solve nonstandard problems. The solution of non-standard problems in the teaching of physics in general secondary schools should be organized in such a way as to maximize the interests of students. Knowing the signs of interest allows the teacher, on the one hand, to select and implement advanced forms and methods of reading. They have the maximum effect on the formation in students of thinking qualities consistent with the specified method. On the other hand, it allows students to check and evaluate the results of their activities on the development of their interests.

In the teaching of physics in general secondary schools, along with the organization of the process of solving non-standard problems, it is necessary to take into account its specific psychological features. They are determined primarily by the content of the science of physics. Getting into the essence of the objects being studied requires students to create abstracts, models, make transitions from one form of abstraction to another, and so on. The second distinctive psychological feature of the interest of 
general secondary school students in solving non-standard problems in physics is that more models and different schemes, tables, graphs, pictures, formulas, diagrams and histograms are used to increase the interest in solving nonstandard problems in physics.

The third distinctive psychological feature of the interest of general secondary school students in solving non-standard problems related to physics is the use of laboratory, physics practicum management. The fourth distinctive psychological feature of the interest of general secondary school students in physics is its use in solving non-standard problems. The fifth distinctive psychological feature of general secondary school students 'interest in physics is its high sensitivity to the use of exercises and problem-solving associated with students' independent performance of non-standard problems.

These psychological features should be taken into account in the purposeful activity of teachers in the formation of students' perception of non-standard problems in physics at different levels, the formation of specific imaginary actions (analysis, comparison, abstraction, generalization, synthesis, etc.).

\section{Conclusions}

1. Composition of oral and written knowledge in the development of students' interest in physics, the formation of knowledge, skills, abilities and competencies in solving nonstandard problems.

2. To teach students to know real facts in the process of solving non-standard problems based on the laws of physics in order to increase their interest in physics.

3. To form students' scientific outlook in solving non-standard problems in developing their interest in physics.
4. Solving non-standard problems in developing students' interest in physics develops their logical thinking and abstract thinking.

5. To create opportunities for students to apply theoretical knowledge in practice in solving non-standard problems in developing their interest in physics.

\section{REFERENCES}

1. Raimov G'. F. Psychological components of non-standard situations in solving nonstandard problems in the "Mechanics" section of physics. - Tashkent: // School and life.- 2020.

2. Raimov G'. F. Features of the student's educational and creative abilities in solving non-standard problems of the "Mechanics" department of physics. -Tashkent: // School and life.- 2020. -4-issue.-P.31-33.

3. Raimov G'. F. Methods of solving nonstandard problems in school physics.Namangan: NamSU Bulletin.-2020.-Issue 7.-P 300-303. 